\title{
CÂMPUS GLÓRIA: OS IMPACTOS SOCIOAMBIENTAIS DA EXPANSÃO DA UNIVERSIDADE FEDERAL DE UBERLÂNDIA
}

\section{Glória Campus: the social and environmental impacts of Federal University of Uberlândia expansion process}

\author{
Élisson Cesar Prieto \\ Prof. Dr., Instituto de Geografia, Universidade Federal de Uberlândia \\ elisson@ig.ufu.br \\ Marlene Teresinha de Muno Colesanti \\ Profa. Dra., Instituto de Geografia, Universidade Federal de Uberlândia \\ mmuno@ufu.br
}

Artigo recebido em 13/07/2012 e aceito para publicação em 17/08/2012

RESUMO: A implantação do câmpus Glória da Universidade Federal de Uberlândia é um projeto desenhado pela universidade desde a década de 1970 que somente agora se torna realidade, graças à política de expansão das universidades federais. O projeto do novo câmpus da UFU, discutido com a comunidade universitária e externa entre 2010 e 2011, foi aprovado e teve sua implantação iniciada com a construção dos primeiros prédios. Esse trabalho fruto de discussões realizadas no Programa de Pós-Graduação em Geografia e desenvolvido no âmbito de um projeto institucional da própria universidade, avalia os efeitos e impactos urbanísticos, ambientais e socioeconômicos da implantação do novo câmpus, a partir dos atuais usos e predominâncias da área que soma quase $5 \%$ do perímetro urbano da cidade de Uberlândia e das propostas elaboradas durante os processos do plano diretor físico territorial, do projeto urbanístico e dos estudos de impacto ambiental e urbanístico, discutindo a necessidade e a viabilidade desse grande empreendimento para a cidade e região.

Palavras-chave: Universidade, câmpus universitário, impactos socioambientais

ABSTRACT: Glory campus implementation is a project designed by the university since the 1970s that only now becomes a reality, after an expansion governmental project for federal universities. The design of the new campus of the UFU, discussed with the university and external community between 2010 and 2011, had been approved by higher council and its implementation started with the construction of the first buildings. This work, result of discussions held at the Geography Posgraduate Program and developed within an institutional project of the university, assesses the effects and impacts of urban, environmental, social and economic aspects of the new campus implementation, from the current uses and predominances of the area which sums almost $5 \%$ of the Uberlândia urban area and proposals made during the master plan and urban design process and environmental and urban impact studies, discussing the necessity and feasibility of this great project for city and region.

Key words: University, Campus, Environmental and social impacts 
Câmpus Glória: os impactos socioambientais da expansão da Universidade Federal de Uberlândia Élisson Cesar Prieto, Marlene Teresinha de Muno Colesanti

\section{INTRODUÇÃO}

A Universidade Federal de Uberlândia, fundada em 1969 e federalizada em 1978 possui 7 câmpus universitários (sendo 4 em Uberlândia), cerca de 23 mil estudantes de graduação e pós-graduação, 3,2 mil técnicos administrativos e 1,5 mil docentes, e um orçamento anual próximo de R\$ 1 bilhão de reais. É uma instituição com 72 (setenta e dois) cursos de graduação e 30 (trinta) programas de pós-graduação em todas as grandes áreas do conhecimento.

Muito se discute sobre a história da educação ou sua relevância social, sobre a pedagogia e os métodos de aprendizagem e avaliação e ou a relação professor-estudante, mas pouco se pesquisa e se produz sobre a infraestrutura escolar e a questão dos espaços físicos que as instituições educacionais ocupam nas cidades. Pouco também se debate a relação que as escolas e as universidades estabelecem com sua localidade.

O presente trabalho busca analisar a área do Glória, pertencente à UFU e que sediará seu novo câmpus, como um espaço do saber, objetivando entender a relação dos espaços educacionais com o meio físico e territorial que eles ocupam.

A implantação do Câmpus Glória, porém, é um sonho perseguido pela instituição desde os anos 1970. A área que já foi utilizada como manancial de águas da cidade, depois como fazenda experimental, passará nos próximos anos a abrigar grandes construções e mudanças em seu uso para torná-la o principal espaço acadêmico da UFU.

O artigo, além de resgatar o histórico da ocupação da gleba denominada Glória, conceita e caracteriza Uberlândia como uma cidade universitária. Em seguida, é apresentado o projeto institucional Câmpus Glória no processo de elaboração do seu plano diretor. Por fim, a partir da delimitação dos principais e mais relevantes desafios colocados para a universidade $\mathrm{e}$ para a cidade de Uberlândia, reflete-se sobre os efeitos socioambientais da implantação do novo câmpus.

Como todo um grande empreendimento, a construção de um câmpus universitário deve possuir alternativas para enfrentar e superar os desafios e os obstáculos que se colocam, de ordem financeira ou estrutural ou com relação aos impactos sobre o meio ambiente (natural e construído), o trânsito e transporte, a vizinhança, a ordenação urbana da cidade.

As reflexões e pesquisas realizadas no Programa de Pós-Graduação em Geografia e no âmbito de um projeto institucional da própria universidade, com apoio de diversos profissionais de várias áreas e coordenado pelo primeiro autor, deram origem ao trabalho apresentado sinteticamente neste artigo, considerando a implantação desse novo espaço universitário como viável, necessária e vantajoso, com enormes potencialidades para a UFU e para a cidade.

\section{UBERLÂNDIA: CIDADE UNIVERSITÁRIA}

Comumente ouvimos falar que Uberlândia é uma cidade universitária, pela presença da Universidade Federal de Uberlândia e pelo seu papel no desenvolvimento do município. A implantação de uma universidade pública em Uberlândia gerou impactos sócioeconômicos significativos, principalmente quanto ao crescimento populacional, à arrecadação de tributos e ao desenvolvimento de novas ideias e culturas.

Entretanto, a instituição da UFU e o crescimento da cidade acarretaram problemas ambientais, especulação imobiliária, expansão de periferias, pobreza nas ruas, carência de habitações, dentre outros (SOARES, 1995, p. 167).

Uberlândia conta atualmente com 24 (vinte e quatro) estabelecimentos educacionais de ensino superior sediados ou com instalações na cidade, sendo duas instituições federais e todas as demais particulares ( 9 delas dedicadas à educação à distância), ostentando o título de maior pólo educacional da região do Triângulo Mineiro.

De acordo com o Censo da Educação Superior (INEP, 2011), Uberlândia tem cerca de 46 mil estudantes de graduação em cursos presenciais, em instituições para as quais convergem estudantes da própria região do Triângulo, do sul do Estado de Goiás, do interior do Mato Grosso, Mato Grosso do Sul e São Paulo, além de mineiros de outras partes do Estado, que aspiram desenvolver seus conhecimentos culturais, científicos e profissionais.

Somados aos cerca de 117 mil (cento e dezessete mil) estudantes matriculados do ensino fundamental até o ensino médio, que a cidade possui, 
segundo dados do Censo Escolar 2011 (INEP, 2011), chega-se ao contingente de mais de 160 mil estudantes, consolidando Uberlândia enquanto pólo que exerce uma centralidade na área educacional.

Uberlândia está localizada na parte oeste do Estado de Minas Gerais, na região do Triângulo Mineiro que abrange 35 (trinta e cinco) municípios, sendo Uberlândia, Uberaba, Ituiutaba, Araguari e Frutal, as maiores cidades.

A ocupação e a posterior urbanização das cidades da região do Triângulo Mineiro são marcadas sobremaneira pela influência de sua posição geográfica estratégica no contexto econômico nacional. Segundo Beatriz Soares (1997, p. 111-112) a ocupação do Triângulo inicia-se no século XVII, quando a região era um ponto de passagem de mineradores e tropeiros; com a descoberta de ouro e diamantes no interior de Goiás e Mato Grosso, formaram-se os primeiros arraiais nas terras do chamado Sertão da Farinha Podre (atual Triângulo Mineiro), em decorrência do afluxo de pessoas em direção ao Brasil Central, em busca de riquezas; e no início do século XIX, novas concessões de terras deram origem às aglomerações urbanas das atuais cidades do Prata, Uberaba e Uberlândia.

A situação geográfica do Triângulo - no caminho de importantes rotas comerciais - e projetos de desenvolvimento entre as décadas de 1940 e 1970, como a "Marcha para o Oeste" de Getúlio Vargas, a construção de Brasília, a política de descentralização industrial de 1960 e já em 1970, os planos de estímulo à agropecuária para exportação no cerrado foram os principais fatores que impulsionaram a inserção do Triângulo Mineiro na economia nacional (GOMES, et. al., 2003, p. 16-18).

O somatório desses acontecimentos tem como resultado, fazer com que Uberlândia, a partir da década de 1940 , tenha tido um crescimento populacional considerável, saltando de 22 mil habitantes para $231 \mathrm{mil}$ em 1980, quando consolida-se em essa centralidade.

Suely Del Grossi (1993) afirma que "A população do município de Uberlândia, teve em 40 anos, um crescimento demográfico acentuado, que se acelera na década de 60-70, quando em apenas 10 anos sua população dobra, (...). Esse quadro impressiona ainda mais quando se verifica que esta população é predominantemente urbana". (apud GOMES, et. al., 2003, p. 20-21).
A título comparativo, no Brasil o crescimento populacional total de 1940 a 1980, segundo o Instituto Brasileiro de Geografia e Estatística - IBGE, foi de $188 \%$ - pulou de 41 milhões para 119 milhões -, enquanto Uberlândia alcançou o percentual de 471\%.

O crescimento demográfico, o desenvolvimento econômico e a intensa urbanização elevaram Uberlândia aos postos de cidade média e a principal polo do Triângulo Mineiro. Com essas condições favoráveis, logo, grandes grupos atacadistas e empresas das áreas de agroindústria, cigarros, de bebidas e alimentos, dentre outras, inclusive de serviços sofisticados como telecomunicações, se instalaram em Uberlândia, com o intuito de usufruir dessa posição estratégica para a distribuição de mercadorias e da infraestrutura favorável ao desenvolvimento econômico da cidade e da região.

Com a implantação desses empreendimentos, vários serviços de apoio às atividades econômicas e atividades complementares, como setores de transporte, educacional, saúde, hotelaria, bancos, se desenvolveram.

Isso possibilitou a estruturação de uma rede urbana polarizada em Uberlândia com influência na região do Triângulo Mineiro e que se estende até o Alto Paranaíba, e municípios do interior de Goiás e São Paulo. Segundo Bessa e Soares (1999, p. 16),

Na nova estruturação da rede urbana regional, Uberlândia projetou-se enquanto cidade-pólo, à medida que criou uma significativa área de polarização, exercendo um poder de comando sobre suas áreas circundantes, passando a subordinar outros municipios com menor concentração demográfica e menor diversidade de funções, bem como concentrando parte importante das atividades e dos recursos, tornando-se o principal centro de recepção e emissão das modernizações.

Esse status, para Uberlândia, de polo regional do Triângulo Mineiro, reivindicado por uma oligarquia formada por empresários e proprietários rurais e urbanos, desde a década de 1950, foi usado como justificativa para que fosse solicitada aos poderes públicos a implantação de escolas de ensino superior na cidade. 
Câmpus Glória: os impactos socioambientais da expansão da Universidade Federal de Uberlândia Élisson Cesar Prieto, Marlene Teresinha de Muno Colesanti

O anseio da sociedade uberlandense pela implantação de cursos superiores fazia parte de um projeto desenvolvimentista das forças políticas e econômicas da cidade e foi determinante para a instalação das primeiras escolas e faculdades. Na verdade, esse anseio podia ser traduzido em uma simbologia: a de que a abertura de faculdades significaria mais progresso à cidade, uma meta há muito perseguida pela elite local.

\section{A UFU E A ÁREA DO GLÓRIA}

A Universidade Federal de Uberlândia é uma instituição com 40 anos de fundação. Os primeiros cursos superiores - Música e Direito - foram criados nos finais dos anos 1950 e vários outros se consolidaram no curso das décadas de 1960, chegando à reunião de escolas e faculdades na Universidade de Uberlândia (UnU) em 1969.

O estudo sobre o espaço físico da UFU, não pode deixar de ser também um estudo, como ressalta Y. F. Tuan (1979), sobre esse espaço vivido, repleto de de ideias, de sensações, de visões. Esse trabalho foi iniciado em 2004/2005, pelos autores, orientando de Mestrado e orientadora, na dissertação "Os Desafios Institucionais e Municipais da implantação de uma cidade universitária: o Câmpus Glória da Universidade Federal de Uberlândia" (PRIETO, 2005).

Em outra obra de referência " $A$ UFU no Imaginário Social" (CAETANO; DIB, 1988), o espaço físico da universidade foi apresentado a partir do projetos alternativos e dos projetos instituídos, com o propósito de demonstrar como o debate em torno das instalações físicas assume importância crucial na definição do que se compreende como "Universidade", inserindo a expansão do espaço universitário na dinâmica do processo de urbanização da cidade.

Em muitos momentos, a história da UFU se confunde com a da cidade e vice-versa. Por isso, é sempre importante contextualizar a formação dos espaços ocupados pela universidade em relação à história da formação urbana da cidade de Uberlândia.

Em muitos momentos, a história da Universidade Federal de Uberlândia realmente se confunde com a da cidade e vice-versa. Por isso, foi importante contextualizar a formação dos espaços ocupados pela universidade em relação à história da formação urbana da cidade de Uberlândia.

A área do Glória passou ao patrimônio da universidade, na época ainda Universidade de Uberlândia (UnU), uma reunião das escolas particulares, estadual e federal existentes, no início da década de 1970. A Reitoria da universidade procurava obter uma área para o câmpus através de doação da Prefeitura. Conforme relata o então Reitor, Prof. Juarez Altafin, com a instalação da usina de Sucupira, os mananciais do Glória e do Jataí foram desativadas e o município ficou com duas grandes áreas disponíveis. Ocorre que o então Prefeito Virgílio Galassi tinha um plano secreto para fazer um clube popular e um estádio na área do Jataí, atual Parque do Sabiá, então a Reitoria pensou no Glória. Como estratégia pediu primeiro a área do Jataí, mas diante da recuso pelo plano do clube popular, a Prefeitura aceitou transferir, sem qualquer custo para a universidade, toda a área do Glória, que era o plano original do então Reitor (CAETANO; DIB, 1988, p. 345).

A doação da área do Glória à Fundação Universidade de Uberlândia foi obtida com a aprovação e sanção da lei municipal n. ${ }^{\circ} 1.966$ em 04 de outubro de 1971. Mais tarde, em 1975, foi concluída uma permuta com uma nova área inserido no projeto do câmpus.

A área do Glória está localizada na parte sudeste do município de Uberlândia às margens da BR-050, no Km 78, entre as coordenadas $18^{\circ} 57^{\prime} 30^{\prime \prime} \mathrm{S}$ e $48^{\circ} 12^{\prime} 0^{\prime \prime} \mathrm{W}$. De acordo com o zoneamento da cidade, a área do Glória fica entre os setores Sul e Leste de Uberlândia, como se depura na figura 1.

Na setorização do perímetro urbano, importante para estipulação legal ou costumeira, dos usos do solo, conforme aponta William Rodrigues Ferreira (2002, p. 76), Uberlândia apresenta o seguinte quadro:

- Setor Central: serviços e comércio, contrastando novos e grandes edifícios de luxo com edificações históricas;

- Setor Sul: loteamentos fechados de luxo e clubes campestres destinados a atender os grupos de renda alta e centros universitários e faculdades;

- Setores Leste e Oeste: expansão dos loteamentos periféricos e conjuntos habitacionais destinados à população de baixa renda, com presença de favelas e loteamentos irregulares;

- Setor Norte: expansão do distrito industrial. 
Figura 1. Mapa de localização dos câmpus (Santa Mônica, Umuarama e Educa) e Fazendas Experimentais (Capim Branco e Glória) na cidade de Uberlândia - MG

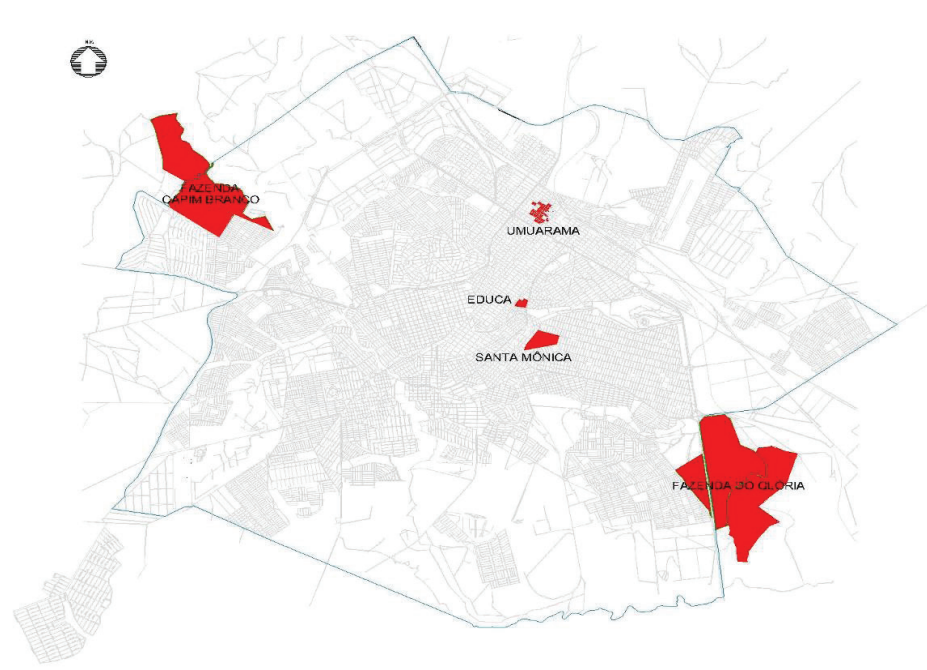

Fonte: UFU, Relatórios DIROB, 2009.

O Setor Sul de Uberlândia possui uma parte nobre, formadas por bairros de alto padrão e condomínios fechados, acentuando os contrastes principalmente com áreas vizinhas de habitações populares, como o Shopping Park, Santa Luzia, São Jorge.

Nessa região mais nobre do Setor Sul, já são quatro as instituições de ensino superior implantadas: UNITRI, UNIESSA, Faculdade Pitágoras e Faculdade Politécnica, todas ao longo do eixo sul da cidade dando também um contorno de modernização pela educação. A implantação dessas faculdades no eixo Sul da cidade impactou fortemente sobre a ordenação urbana, principalmente no que se refere ao trânsito. Apesar disso, são poucos os estudos sobre impacto e o processo de licenciamento desses empreendimentos.
Quando implantado o Câmpus Glória, o Setor Sul ficará efetivamente consolidado como área universitária da cidade, apesar de utilizar, diferente das demais instituições, o eixo leste (avenida João Naves de Ávila) como acesso principal.

Os principais acessos à fazenda experimental do Glória são a avenida João Naves de Ávila para aqueles que vem dos setores Central, Oeste e Sul da cidade e a BR-050 para aqueles que vem dos Setores Norte e Oeste. Como são vias rápidas, o deslocamento é facilitado, permitindo inclusive a utilização de transporte coletivo do tipo expresso (com poucas paradas).

A tabela abaixo demonstra que, mesmo em relação a pontos centrais da cidade, a distância e o tempo necessários ao percurso, não fazem da área do Glória, uma localidade distante e de difícil acesso.

Tabela 1. Distâncias de pontos da cidade em relação à portaria da Fazenda do Glória

\begin{tabular}{l|l|l}
\hline Ponto & Distância & Tempo* \\
\hline Rodoviária & $9 \mathrm{~km}$ & $16 \mathrm{~min}$ \\
\hline Praça Tubal Vilela (Centro) & $8,7 \mathrm{~km}$ & $15 \mathrm{~min}$ \\
\hline Terminal Central & $7,8 \mathrm{~km}$ & $13 \mathrm{~min}$ \\
\hline Campus Umuarama & $10 \mathrm{~km}$ & $13,5 \mathrm{~min}$ \\
\hline Campus Educação Física & $8 \mathrm{~km}$ & $11 \mathrm{~min}$ \\
\hline Campus Santa Mônica & $6,3 \mathrm{~km}$ & $8 \mathrm{~min}$ \\
\hline Terminal Santa Luzia & $1,9 \mathrm{~km}$ & $2,5 \mathrm{~min}$ \\
\hline
\end{tabular}

* tempo considerado a partir de trajetos percorridos de carro em horário comercial (PRIETO, 2005) 
A área escolhida para implantação do câmpus é pertencente à Universidade Federal de Uberlândia, apesar de reunir diversas matrículas diferentes, conforme se vê da figura 2. A área referida é constituída de glebas contíguas, sendo duas de propriedade da UFU e uma pertencente à Fundação de Assistência, Estudo e Pesquisa de Uberlândia (FAEPU).

A área do câmpus é formada pelas denominadas no mapa de Área 1(A) e Área 2, totalizando uma área de 293 hectares 70 acres e 44 centiacres, ou 2.937.044,00 $\mathrm{m}^{2}$ (dois milhões novecentos e trinta e sete mil e quarenta e quatro metros quadrados).
A área 1 indicada na figura 2, localizada na porção central, foi doada pela Prefeitura Municipal de Uberlândia em 1973, justamente com o objetivo de que na área fosse implantado um câmpus único para a UFU. Essa área foi separada pela implantação da rodovia BR-050 (Uberlândia-Uberaba), sendo que do lado direito está a sede da fazenda e a área esportiva ocupada anteriormente pela ASUFUb; e do lado esquerdo, a área conhecida como "triângulo", já inserida na malha urbana e contígua ao bairro São Jorge.

Figura 2. Mapa de divisão das glebas da Fazenda do Glória

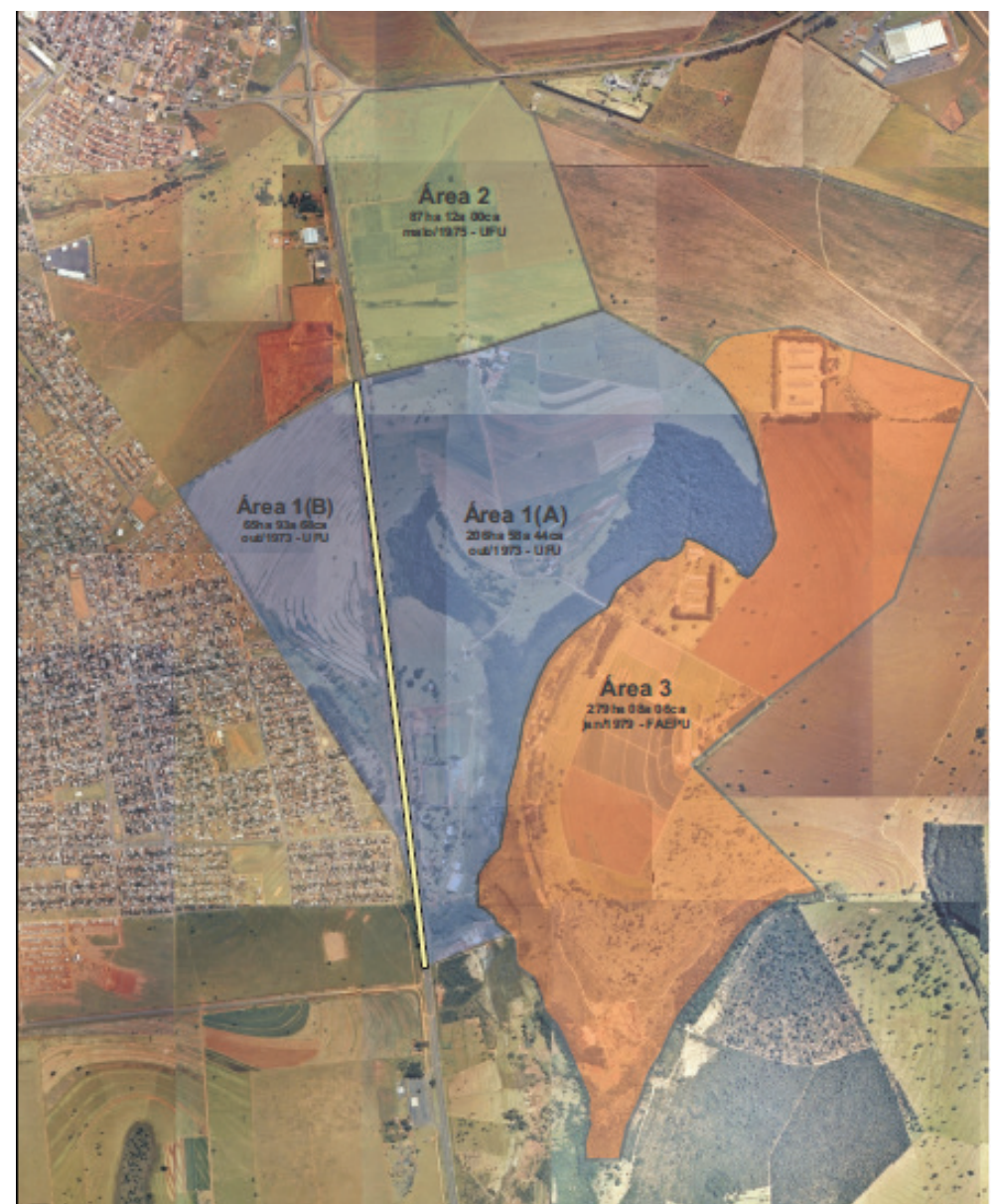

Fonte: PRIETO, 2005 (Atualizado, 2010)

A área 2, localizada na porção norte da área, no cruzamento da BR-050 (Uberlândia-Uberaba) com a BR-365 (Uberlândia-Patrocínio), foi trocada pela área pertencente ao Parque de Exposições do Camaru, que havia sido doado pela prefeitura à universidade.
A área 3, localizada na porção leste e sul, foi adquirida pela FAEPU em 1979, e tem área de 279 hectares 14 ares 27 centiares. Atualmente, esta área é utilizada como fazenda experimental e não faz parte da proposta do Câmpus Glória. 
Tabela 2. Áreas conforme Levantamento Topográfico

\begin{tabular}{l|c|c}
\hline \multicolumn{1}{c|}{ TIPO } & ÁREA $\left(\mathbf{m}^{\mathbf{2}}\right)$ & \% em relação à área total \\
\hline Área do Câmpus (Fazenda Glória) & $2.937 .044,00 \mathrm{~m}^{2}$ & $45,98 \%$ \\
\hline Área da FAEPU & $2.791 .427,00 \mathrm{~m}^{2}$ & $43,70 \%$ \\
\hline Área do Triângulo & $659.388,00 \mathrm{~m}^{2}$ & $10,32 \%$ \\
\hline TOTAL & $\mathbf{6 . 3 8 7 . 8 5 9 , 0 0 ~ \mathbf { m } ^ { 2 }}$ & $\mathbf{1 0 0 , 0 0 \%}$ \\
\hline
\end{tabular}

Fonte: Levantamento Topográfico, 2010.

A área do Glória impressiona pela dimensão, equivalente a quase $5 \%$ do perímetro urbano de Uberlândia, e tem na diversidade da natureza seu maior atrativo. É uma fazenda experimental e comercial, mas ao mesmo tempo, uma reserva de vegetação e animais silvestres, com córregos, represa e paisagens naturais.

No entorno da área encontramos:

- ao norte, a BR-365, Ferrovia Centro-Atlântica e vazio urbano com loteamentos residenciais de média renda em fase de diretrizes urbanísticas;

- ao leste, propriedades rurais particulares e da fundação de apoio da UFU (FAEPU) e pelo Entreposto da Zona Franca de Manaus (área para grandes empresas, centro de atacado e distribuição e distrito industrial limpo);

- ao sul, empreendimentos rurais de pequeno porte, pelo futuro prolongamento do anel viário Sul de Uberlândia e, mais à frente, pelo rio Uberabinha;

- a oeste, BR-050, com área residencial conhecida como "triângulo do Glória" e pelos bairros São Jorge, Laranjeiras e Seringueiras (de baixa renda).

Quanto à hidrografia, na área do Glória estão as nascentes do córrego do Glória - que dá nome a toda a fazenda e é um dos afluentes da margem direita do Rio Uberabinha. O rio Uberabinha, com $118 \mathrm{~km}$ (cento e dezoito quilômetros) de extensão, integra a bacia do Rio Araguari, nascendo ao norte de Uberaba e atravessando Uberlândia até o Rio Araguari, a noroeste do município. Atualmente, a bacia do rio Uberabinha é o único manancial utilizado no abastecimento de água para a população da cidade de Uberlândia. Até a década de 1960, o córrego do Glória, junto com o córrego Jataí, eram os mananciais que abasteciam a cidade. A área ainda possui uma represa sobre terra com capacidade para 31 mil metros cúbicos (ou 31 milhões de litros) de água (Carta Cachoeira do Sucupira, 1970).

Segundo o estudo "Mapeamento Temático da Bacia do Córrego Glória em Uberlândia MG, utilizando o software Idrisi”, a Bacia do Córrego Glória abrange uma área total de $12,5 \mathrm{~km}^{2}$ (doze vírgula cinco quilômetros quadrados) (ROSA, et. al., 2004:s/p).

$\mathrm{O}$ solo encontrado na maior parte da área do Glória é o Latossolo Vermelho-Escuro Distrófico (LEd), que é um tipo de solo muito fértil e propício à agricultura. A altitude na área varia entre 840 metros (na parte baixa, próxima ao curso d'água do córrego do Glória) a 939 metros (no plano próximo à BR-365), segundo o levantamento topográfico (2010).

Com relação à geomorfologia, a Bacia do Córrego Glória se enquadra na categoria de áreas de relevo medianamente dissecado que corresponde ao setor com topos aplainados entre 700 e 900 metros de vertentes suaves, interrompidas por locais mantidas pela laterita, onde ocorrem pequenos anfiteatros mais convexizados e elaborados, preferenciais para o afloramento do lençol subterrâneo (Baccaro, 1989 apud ROSA, et.al., 2004:s/p).

Com relação aos aspectos ambientais, há a presença marcante de vegetação e hidrografia, com espécimes de fauna e flora bem representativos do Cerrado, localizados nas áreas de preservação permanente (APP) do córrego do Glória e de reserva legal da fazenda.

O quadro a seguir sintetiza as áreas cobertas por vegetação e outras funções ambientais, referentes ao perímetro do câmpus: 
Câmpus Glória: os impactos socioambientais da expansão da Universidade Federal de Uberlândia Élisson Cesar Prieto, Marlene Teresinha de Muno Colesanti

Tabela 3. Áreas de interesse ambiental e cobertura vegetal

\begin{tabular}{c|c|c}
\hline \multicolumn{1}{c|}{ Tipo } & Áreas & \multirow{2}{*}{ \% em relação à área total } \\
\cline { 1 - 2 } Área Úmida (a) & $341.320,625 \mathrm{~m}^{2}$ & \multirow{2}{*}{$12,39 \%$} \\
\cline { 1 - 2 } Barragem e curso d'água (b) & $22.588,641 \mathrm{~m}^{2}$ & \\
\cline { 1 - 2 } Área de Preservação Permanente (APP) (c) & $203.408,00 \mathrm{~m}^{2}$ & $6,93 \%$ \\
\hline Reserva Legal (d) & $167.294,05 \mathrm{~m}^{2}$ & $5,70 \%$ \\
\hline Área de Mata nativa & $237.486,242 \mathrm{~m}^{2}$ & \\
\hline TOTAL $(\mathbf{a}+\mathbf{b}+\mathbf{c}+\mathbf{d})$ & $\mathbf{7 3 4 . 6 1 1 , 3 2} \mathbf{~ m}^{\mathbf{2}}$ & $\mathbf{2 5 , 1 0 \%}$ \\
\hline
\end{tabular}

Fonte: Levantamento Planialtimétrico, 2010.

Essas áreas de interesse ambiental, como se vê onde boa parte, não está mais recoberta por vegetação nativa e em que a Reserva Legal é inferior aos limites mínimos legais, foram, na verdade parcialmente utilizadas para atividades agrícolas. Com a incorporação do Glória ao patrimônio da universidade, a área passou a ser utilizada como fazenda experimental, servindo às atividades acadêmicas de cursos de graduação e pós-graduação da UFU, principalmente Agronomia e Medicina Veterinária.

Quanto à infraestrutura existente, além das edificações destinadas à utilização como fazenda experimental, destaca-se a inexistência de redes de esgoto (presença de fossas sépticas) e de redes de drenagem de pluviais, abastecimento de água por poço tubular e captação superficial em curso d'água e barragem (com de adutora de água da estação Sucupira passando pela área) e da precariedade dos serviços de comunicação e energia elétrica.

Atualmente, é possível identificar quatro tipos de usos e predominâncias na área:

1. Agricultura e criação animal: atividades de agricultura e criação desenvolvidas na fazenda, possuindo caráter experimental e comercial: criação de gado de leite; produção de frutas de verduras, sendo que ambas abastecem o restaurante universitário do Câmpus Santa Mônica e Hospital de Clínicas; e silagem, para alimentação do gado.

2. Reserva ambiental: existência de uma extensa reserva de proteção, composta de Área de Preservação Permanente (APP) e Reserva Legal de vegetação nativa $(R L)$, começando nas duas nascentes do córrego do Glória e ao longo de suas margens até o deságüe no rio Uberabinha.

3. Parque esportivo: que, na verdade, era o clube social e recreativo da Associação dos Servidores da Universidade Federal de Uberlândia - ASUFUb, com aproximadamente 46 (quarenta e seis) hectares, constituída por 2 piscinas, 5 quadras poliesportivas, 3 campos de futebol, uma pista de atletismo, além de vestiários e outras edificações de uso social. Tais construções estão, apesar do bom estado de conservação, sem qualquer utilização há vários anos.

4. Área sem utilização: grande parte do território encontra-se ainda hoje sem qualquer uso ou ocupação, tais como a gleba conhecida como triângulo do Glória que fica do outro lado da BR-050, ao lado no bairro São Jorge e dentro do perímetro urbano; o terreno próximo ao viaduto de confluência das BR-050 e BR-365; as pastagem degradadas que se encontram em várias partes da gleba do Glória e não são utilizadas. A principal preocupação com relação a essas áreas subutilizadas ou não utilizadas na fazenda do Glória é o descumprimento, por um órgão público, da função social e ambiental da propriedade, seja daquela já situada no perímetro urbano de Uberlândia (que inclusive no início de 2012 foi ocupada por famílias sem teto), seja daquelas áreas rurais.

\section{PROJETO CÂMPUS GLÓRIA}

O Câmpus Glória foi aprovado a primeira vez em 1973, em reunião do Conselho Universitário que atestou a importância de reunir escolas e facul- 
dades em um câmpus universitário. Contudo, a falta de recursos para o projeto acabou consolidando os câmpus Santa Mônica e Umuarama, onde já existiam edificações de ensino.

Após discussões inconclusivas já nos anos 2000 sobre espaço físico, somente em 2007 e 2008, com a plano de expansão das universidades federais (REUNI), com recursos para novos cursos e vagas, a constituição de um novo câmpus em Uberlândia voltou à tona. Em 2008, o Conselho Universitário, aprovou uma resolução criando o Câmpus Glória e dispondo que o Plano Diretor e o Projeto Urbanístico deveriam ser elaborados posteriormente.

Com a inclusão do câmpus e das obras previstas no Plano Institucional de Desenvolvimento e Expansão (PIDE 2010-2015), o projeto Campus Glória tornou-se uma ação da UFU. O encaminhamento prático foi iniciar o processo de elaboração do Plano Diretor Físico-Territorial do Câmpus Glória, onde deveriam constam os princípios, diretrizes, normas, instrumentos e mapas de propostas para a ocupação do câmpus, de forma participativa.

Esse trabalho foi iniciado em junho de 2010, com a definição pela Administração Superior da UFU, de que o Plano Diretor seria elaborado por uma equipe multidisciplinar da própria universidade, composta por professores, técnicos administrativos, estudantes estagiários e colaboradores.

A elaboração do Plano Diretor compreendeu a definição da área do câmpus e dos acessos, a realização de diagnóstico físico-ambiental, a elaboração de proposta de morfologia, zoneamento e ocupação da área, a realização de estudos de impactos ambiental e de vizinhança, o licenciamento ambiental e urbanístico do câmpus, a definição de prioridades, princípios e diretrizes gerais para implantação do Câmpus Glória, tudo isso, envolvendo a comunidade universitária e colaboradores com experiências em planejamento de outras universidades e profissionais da cidade e região.

O Plano Diretor foi elaborado pelo Grupo de Trabalho Técnico (GTPD-Glória), após a realização de um processo de discussão coletiva e transparente, embasado em reflexões e contribuições de dezenas de reuniões internas, 6 eventos públicos organizados, um questionário on line e informações disponíveis no website www.campusgloria.ufu.br e um concurso de Ideias Sustentáveis para o câmpus.

Para o planejamento ordenado e sustentável desse espaço (sobretudo para infraestrutura) foi considerada uma expectativa, em 30 anos para consolidação definitiva do câmpus, de uma população de 30 mil estudantes e 10 mil usuários, servidores e prestadores de serviço, totalizando 40 mil pessoas.

Tabela 4. Etapas de Ocupação do Câmpus Glória

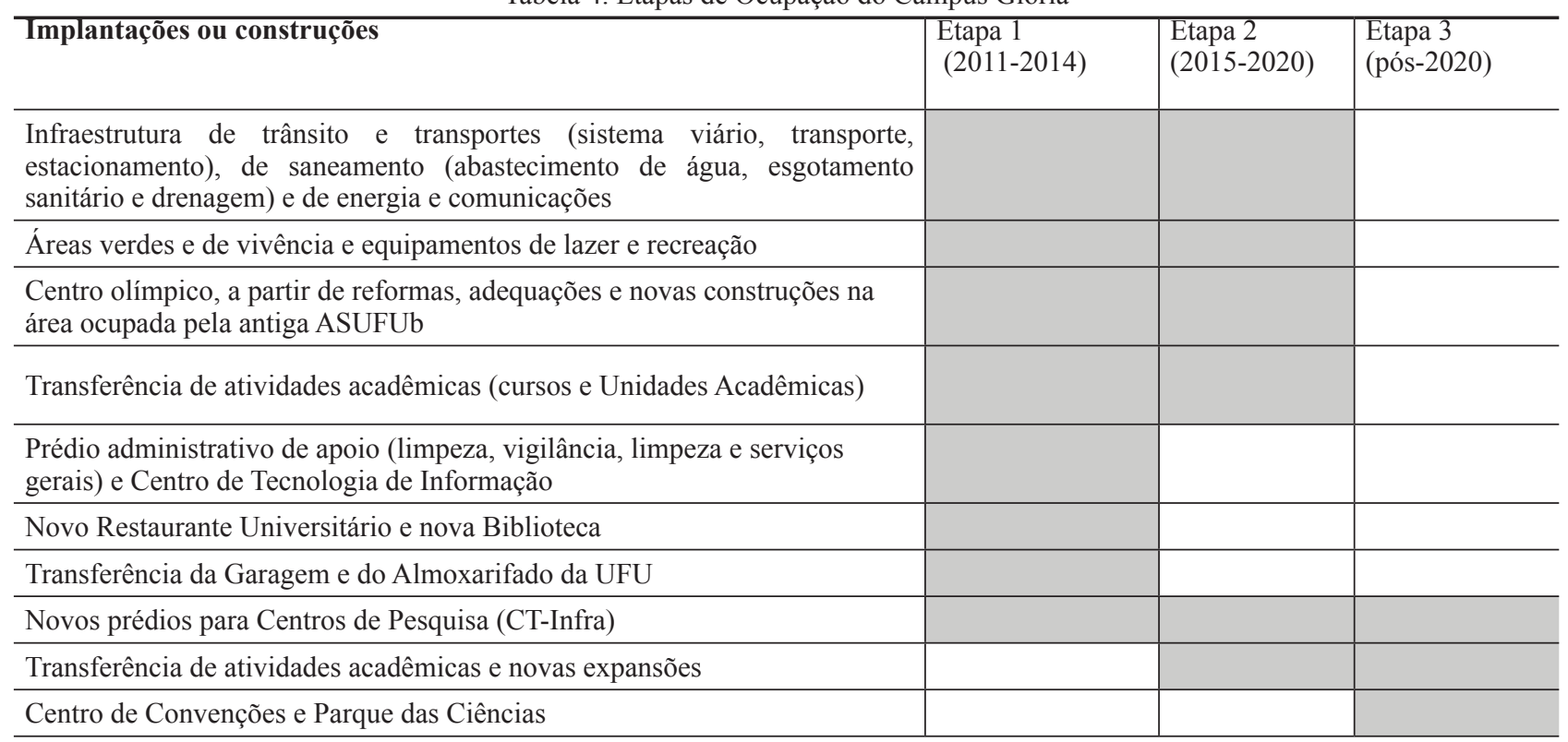

Fonte: Plano Diretor do Câmpus Glória (UFU, 2011) 
Câmpus Glória: os impactos socioambientais da expansão da Universidade Federal de Uberlândia Élisson Cesar Prieto, Marlene Teresinha de Muno Colesanti

O Plano Diretor Físico-Territorial, aprovado pelo Conselho Universitário em setembro e 2011, na forma da Resolução n. ${ }^{\circ} 22 / 2011$, é o documento que orienta todas as ações da universidade com relação à ocupação de espaços físicos do Câmpus Glória, contendo o projeto urbanístico e o detalhamento das etapas de implantação até a futura consolidação como o câmpus que, a longo prazo, abrigará a maior parte das atividades da UFU.

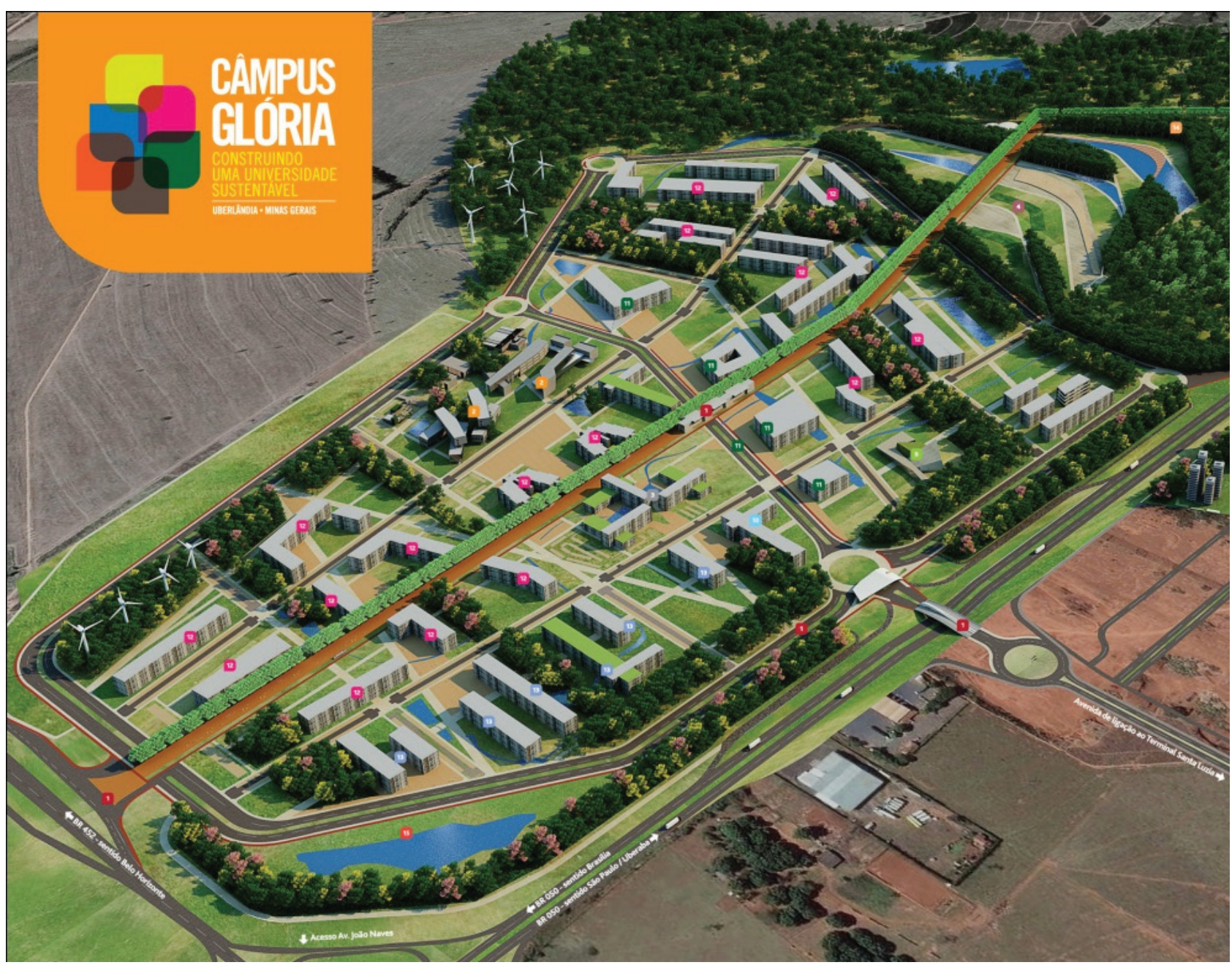

Figura 3. Mapa projetual do Câmpus Glória da UFU. Fonte: UFU, 2012, adaptado.

Além de incorporar o projeto urbanístico e paisagístico de toda a área do câmpus, bem como os projetos arquitetônicos das edificações que serão construídas na primeira fase, o Plano Diretor detalha o zoneamento ambiental e urbanístico do câmpus, prevê a localização de equipamentos que serão implantados ou transferidos, define a concepção da infraestrutura verde e o sistema viário, além das diretrizes gerais de ocupação físico-territorial. Nessa seara, destacam-se as opções relacionadas à sustentabilidade, como infraestrutura verde e ampliação das áreas com vegetação, técnicas construtivas como telhado verde, aproveitamento de água de chuvas e de iluminação e ventilação naturais, sistema de drenagem natural, uso de energia solar e eólica nos prédios, formação de bosques e corredores ecológicos, implantação de ciclovias e tratamento de esgoto e efluentes. 


\section{IMPACTOS SOCIOAMBIENTAIS}

Não há dúvidas que o Câmpus Glória é um grande empreendimento com impactos locais e regionais, com impactos positivos e negativos sobre o ambiente. Para avaliação os chamados efeitos socioambientais, é apresentada a seguir uma síntese dos Estudos de Impacto Ambiental (EIA) e de Vizinhança (EIV), elaborados durante as etapas de discussão do plano diretor e do projeto urbanístico do novo câmpus Glória, para que suas conclusões pudessem ser já incorporadas nesses instrumentos de planejamento.

O Estudo de Impacto Ambiental com o respectivo Relatório de Impacto Ambiental (EIA/RIMA), acompanhado do Estudo de Impacto de Vizinhança (EIV), referente à implantação do Câmpus Glória foi elaborado, por solicitação da Prefeitura Universitária, a partir de um Termo de Referência baseado nas legislações e exigências dos órgãos ambientais do
Estado e do Município de Uberlândia, pelas empresas juniores Terra Consultoria (do curso de Geografia) e MinasBio Consultoria Ambiental (do curso de Ciências Biológicas).

As empresas juniores lideraram, com autonomia, o processo de elaboração dos estudos, com apoio de equipe de professores colaboradores para elaboração do Estudo de Impacto Ambiental e Estudo de Impacto de Vizinhança, que foi nomeada por Portaria do Reitor como integrantes do Grupo de trabalho técnico - CTIA-GLORIA, coordenado pela Profa. Dra. Gelze Campos Rodrigues, do Instituto de Geografia, com colaboração de especialistas de diversas outras áreas do conhecimento.

Nas matrizes apresentadas sinteticamente a seguir, descreveu-se o impacto aferido nas pesquisas para os estudos realizados, bem como a atribuição de uma significância

Tabela 5. Síntese da matriz do Estudo de Impacto de Vizinhança (EIV) do Câmpus Glória

\begin{tabular}{l|l|l}
\hline Impacto & Descrição & Significância \\
\hline Adensamento na região & $\begin{array}{l}\text { Pressão por ocupação do solo e adensamento de áreas vazias com } \\
\text { novas construções (que deve ser de, no máximo, 8.5\% da demanda } \\
\text { espontânea) }\end{array}$ & Pequena \\
\hline $\begin{array}{l}\text { Demanda de equipamentos } \\
\text { urbanos e comunitários }\end{array}$ & $\begin{array}{l}\text { Demanda majoritária de serviços públicos, sobretudo de } \\
\text { infraestrutura e equipamentos urbanos e comunitários }\end{array}$ & Pequena \\
\hline $\begin{array}{l}\text { Alterações no uso e } \\
\text { ocupação do solo }\end{array}$ & $\begin{array}{l}\text { Possível alteração do uso do solo (que é predominantemente } \\
\text { residencial no entorno) em função de substituição por outros usos }\end{array}$ & Pequena \\
\hline $\begin{array}{l}\text { Geração de tráfego e } \\
\text { demanda de transporte }\end{array}$ & $\begin{array}{l}\text { Impacto do empreendimento no aumento de viagens por veículos } \\
\text { motorizados, individuais ou coletivos, para a região }\end{array}$ & Alta \\
\hline $\begin{array}{l}\text { Ventilação, iluminação e } \\
\text { paisagem natural }\end{array}$ & $\begin{array}{l}\text { Impacto sobre elementos com função de preservação do ambiente } \\
\text { natural e construído }\end{array}$ & Pequena \\
\hline Valorização imobiliária & $\begin{array}{l}\text { Demanda direta e indireta por novas áreas de ocupação, ampliando } \\
\text { a pressão inflacionária e especulação da terra }\end{array}$ & Média \\
\hline Riscos à saúde e vida & $\begin{array}{l}\text { Ocorrência de possíveis danos à saúde e vida de trabalhadores e } \\
\text { moradores do entorno }\end{array}$ & Pequena \\
\hline
\end{tabular}

Fonte: Estudo de Impacto de Vizinhança do Câmpus Glória (MINAS BIO e TERRA, 2011)

O Estudo de Impacto de Vizinhança aponta, em suma, que boa parte dos impactos sobre o entorno são inerentes ao próprio desenvolvimento espontâneo da cidade, inclusive por conta do programa Minha Casa Minha Vida, que expande-se para esse eixo Sul-Leste, não tendo o novo câmpus grande influência no adensamento e uso e ocupação do solo.

O principal impacto será sobre a geração de tráfego e demanda de transporte, por causa não apenas do câmpus Glória, mas do adensamento do entorno.
As ampliações no sistema viário serão necessárias e dispendiosas, devendo-se adotar, além da abertura de novas vias e viaduto. projetos para incremento dos transportes coletivos e ciclovias.

Caberá ainda ao poder público exercer um controle e acompanhamento sobre as áreas vazias para evitar a especulação imobiliária e sobre a demanda de novos equipamentos urbanos e comunitários, a partir da elaboração de diretrizes projetuais para os novos parcelamentos do solo. 
Câmpus Glória: os impactos socioambientais da expansão da Universidade Federal de Uberlândia

Élisson Cesar Prieto, Marlene Teresinha de Muno Colesanti

O estudo conclui que, pela natureza das atividades acadêmicas, bem como o desenvolvimento de cenários elaborados para o projeto do câmpus, que revelam uma ação de implantação cuidadosa e que busca ampliar as práticas sustentáveis e sua integração com a vizinhança, a implantação trará benefícios não só para a comunidade imediata (oferta de empregos e dinamização econômica), mas também na escala regional, superando em muito os impactos negativos, os quais deverão ser mitigados com as observações do estudo.

Com relação ao EIA, a matriz considera os impactos sobre o meio físico, biótico e socioeconômico, assim descritos (tabela 6):

Tabela 6. Síntese da matriz do Estudo de Impacto Ambiental (EIA) do Câmpus Glória

\begin{tabular}{|c|c|c|}
\hline Impacto & Descrição & Significância \\
\hline \multicolumn{3}{|l|}{ MEIO FÍSICO } \\
\hline $\begin{array}{l}\text { Desencadeamento de } \\
\text { processos erosivos }\end{array}$ & $\begin{array}{l}\text { Pela supressão da cobertura vegetal atual - pastagem e culturas anuais - } \\
\text { por terraplanagem, compactação e impermeabilização do solo para obter } \\
\text { um terreno com capacidade de suporte para as atividades previstas }\end{array}$ & Pequena \\
\hline $\begin{array}{l}\text { Assoreamento de cursos } \\
\text { d'água }\end{array}$ & $\begin{array}{l}\text { Pela movimentação de terra e a geração de volumes significativos de } \\
\text { material terroso, não coeso, e suscetíveis ao transporte pluvial e pela } \\
\text { deposição de sedimentos decorrentes dos processos erosivos }\end{array}$ & Pequena \\
\hline $\begin{array}{l}\text { Alteração da qualidade das } \\
\text { águas superficiais }\end{array}$ & $\begin{array}{l}\text { Devido ao aporte de sedimentos derivados da erosão e carreamento dos } \\
\text { materiais das obras, podendo provocar o aumento da turbidez, e durante a } \\
\text { operação, pelos } \\
\quad \text { efluentes, sanitários e de laboratórios, que podem causar } \\
\text { contaminação das águas superficiais }\end{array}$ & Pequena \\
\hline Contaminação dos solos & $\begin{array}{l}\text { Pela geração e manuseio de resíduos sólidos de diversas naturezas } \\
\text { (resíduos inertes, da obra civil e até perigosos) }\end{array}$ & Pequena \\
\hline $\begin{array}{l}\text { Redução da recarga hídrica } \\
\text { subterrânea }\end{array}$ & $\begin{array}{l}\text { Devido à retirada de água de poço tubular existente e devido às } \\
\text { edificações e impermeabilização do solo }\end{array}$ & Média \\
\hline Alteração na qualidade do ar & $\begin{array}{l}\text { Devido à ressuspensão de material particulado e da emissão dos gases } \\
\text { veiculares causada pelas obras e pela circulação de veículos }\end{array}$ & Pequena \\
\hline $\begin{array}{l}\text { Alteração dos níveis de } \\
\text { ruídos }\end{array}$ & $\begin{array}{l}\text { Devido ao ruído das máquinas e na fase de operação, pelas atividades } \\
\text { acadêmicas e o fluxo de veículos }\end{array}$ & Pequena \\
\hline Formação de ilhas de calor & $\begin{array}{l}\text { Fenômeno microclimático de contraste em relação às suas temperaturas, } \\
\text { umidade e/ou ventos, quando comparada com as áreas circundantes, } \\
\text { decorrente da concentração de edificações e áreas impermeabilizadas }\end{array}$ & Pequena \\
\hline \multicolumn{3}{|l|}{ MEIO BIÓTICO } \\
\hline $\begin{array}{l}\text { Perda de indivíduos } \\
\text { arbóreos e de habitats }\end{array}$ & $\begin{array}{l}\text { Processo de construção pode implicar na redução do número desses } \\
\text { elementos arbóreos isolados, na redução de recursos alimentares para a } \\
\text { fauna e eliminação de possíveis locais de nidificação }\end{array}$ & Pequena \\
\hline Afugentamento da fauna & $\begin{array}{l}\text { Provocado pela supressão da vegetação, movimentação do terra, } \\
\text { circulação de veículos e emissão de ruídos, principalmente avifauna }\end{array}$ & Alta \\
\hline Atropelamento da fauna & $\begin{array}{l}\text { Provocado pela circulação de veículos nas fases de construção e operação, } \\
\text { agravado pela emissão de ruídos e supressão de vegetação }\end{array}$ & Média \\
\hline $\begin{array}{l}\text { Enriquecimento da vegetação } \\
\text { nativa }\end{array}$ & $\begin{array}{l}\text { Impacto positivo da ampliação e enriquecimento da mata ciliar nas APPs } \\
\text { e do cerrado da Reserva Legal }\end{array}$ & Alta \\
\hline \multicolumn{3}{|c|}{ MEIO SOCIOECONÔMICO } \\
\hline $\begin{array}{l}\text { Incômodo à população } \\
\text { residente e nas atividades da } \\
\text { fazenda }\end{array}$ & $\begin{array}{l}\text { Referente às obras, trânsito de veículos e geração de resíduos e ruídos, } \\
\text { gerando incômodo nas famílias que moram na fazenda e nas atividades } \\
\text { realizadas, principalmente de produção animal }\end{array}$ & Pequena \\
\hline $\begin{array}{l}\text { Deslocamento de moradias e } \\
\text { transferência da fazenda }\end{array}$ & $\begin{array}{l}\text { Realocamento de habitações ocupadas por trabalhadores da fazenda e } \\
\text { transferência total de atividades de produção agrícola e animal para a área } \\
\text { da FAEPU }\end{array}$ & Média \\
\hline $\begin{array}{l}\text { Geração de expectativas } \\
\text { de empregabilidade e de } \\
\text { negócios }\end{array}$ & $\begin{array}{l}\text { Expectativa da população do entorno e da área de influência em relação à } \\
\text { empregabilidade e possibilidades de futuros negócios }\end{array}$ & Pequena \\
\hline $\begin{array}{l}\text { Aumento no oferecimento de } \\
\text { serviços educacionais }\end{array}$ & $\begin{array}{l}\text { Oferta de cursos universitários a estudantes de várias regiões, } \\
\text { constituindo-se também em polo educacional e cultural, promovendo } \\
\text { eventos que possam ser compartilhados com os moradores da vizinhança, } \\
\text { de Uberlândia e de outros municípios. }\end{array}$ & Alta \\
\hline
\end{tabular}

Fonte: Estudo de Impacto Ambiental do Câmpus Glória (MINAS BIO e TERRA, 2011) 
No que tange aos impactos sobre o meio físico, todos à exceção da recarga hídrica subterrânea, tem pequena significância. Para fazer mitigar os efeitos negativos foram previstos programa de monitoramento do córrego do Glória, por meio da medição da vazão, dimensionamento dos canais e verificação da qualidade da água; programa de gestão ambiental da construção; programa de monitoramento e contenção de processos erosivos; programa de gerenciamento de resíduos sólidos; além da construção de uma Estação de Tratamento de Esgotos, de uma estação meteorológica e de um plano de arborização.

Quanto ao meio biótico, os impactos de alta significância são referentes ao afugentamento de avifauna (negativo) e enriquecimento da vegetação (positivo), devendo-se registrar que há Áreas de Preservação Permanente e Reserva Legal que precisam ser revegetadas, além de ampliar a cobertura nas áreas atualmente degradadas. Para realização dessas ações, haverá, por sugestão do EIA, um plano de gestão ambiental onde serão executados programa de Monitoramento da Fauna, projeto técnico de reconstituição da flora, isolamento da APP e da Reserva Legal e uso de placas informativas nas suas proximidades. Normas para circulação de veículos e programa de Educação Ambiental à comunidade universitária e externa, demonstrando a importância da conservação dessas áreas de grande valor ambiental e os cuidados na área, também serão necessários.

Com relação aos impactos incidentes sobre o meio socioeconômico há necessidade de uma parceria com o poder público local no sentido da adoção de planos estratégicos de planejamento de ocupação do solo. Caberá à universidade desenvolver programas de Comunicação Social e de Educação Ambiental, estabelecendo uma relação com escolas e com bairros vizinhos para realizar projetos educacionais e sociais no entorno.

O principal impacto socioeconômico será a transferência da fazenda com deslocamento de moradias e outros usos. Contudo, o fato da área da FAEPU ser contígua ao câmpus e extensa, minimizará os impactos e a desmobilização de recursos, possibilitando com planos ordenados, uma ocupação racional e produtiva dos espaços.

Em análise final, de acordo com os Estudos de Impacto de Vizinhança (EIV) e Ambiental (EIA), foram identificados 16 impactos socioambientais decorrentes da implantação e operação do câmpus do Glória, sendo 3 positivos e 13 negativos, mas apenas 2 de alta significância. Considerando a aplicação das ações de gestão socioambiental recomendadas nos estudos, tais efeitos negativos são plenamente reversíveis ou mitigáveis.

Em discussões realizadas sobre o projeto do câmpus na disciplina "Efeitos socioespaciais de grandes empreendimentos", do Programa de Pós-Graduação em Geografia, em 2012, ministrada pelo Prof. Vicente de Paulo da Silva, outras considerações sobre as funções sociais do câmpus, a necessidade de realização de trabalhos de pesquisa e aproximação com escolas e moradores, foram reforçadas.

A execução de todas as ações de gestão (e do Plano de Gestão Ambiental recomendado) é essencial para garantir que os impactos negativos sejam mitigados e a universidade possa utilizar o câmpus, desde sua construção, como um laboratório de pesquisas quanto ao controle e monitoramento dos efeitos socioambientais.

\section{UM CÂMPUS VIÁVEL, NECESSÁRIO E VAN- TAJOSO}

O Câmpus Glória da UFU não é apenas viável, mas já é uma realidade, com as construções dos primeiros prédios para abrigar novos cursos do programa de expansão da universidade. Do ponto de vista técnico, a instalação e operação do Câmpus Glória é também ambientalmente viável na área geográfica escolhida, com as ações ambientais.

A viabilidade socioambiental foi atestada pelos estudos de impacto que concluíram que os efeitos negativos sobre o entorno e sobre os meios físico, biótico e socioeconômico, não causam uma situação de degradação na área diretamente afetada e de influência onde o câmpus irá se instalar e mais, que sua operação contribuirá para a melhoria da qualidade de vida das populações da cidade e de outras regiões.

A implantação do Câmpus Glória é necessária para responder às demandas face ao estrangulamento físico vivido pela universidade, acarretando carência de espaços para novos cursos, bem como atividades 
Câmpus Glória: os impactos socioambientais da expansão da Universidade Federal de Uberlândia Élisson Cesar Prieto, Marlene Teresinha de Muno Colesanti

de pesquisa e extensão, que seriam supridas com transferências pontuais e instalação dos novos cursos e atividades no futuro câmpus.

Além disso, o novo câmpus justifica-se pela necessidade de cumprimento da função social da propriedade, em decorrência das existências de grandes áreas, urbanas e rurais, pouco ou nada utilizadas, que fariam parte do projeto de implantação do câmpus função social do câmpus, "seja enquanto simples espaço físico destinado a atividades próprias do ensino de nivel superior, seja enquanto capacidade instalada à conta de investimentos vultuosos feitos em nome da sociedade que o edifica e o mantém" (NEIVA, 1984, p. 69).

Não bastasse isso, a realidade da cidade e sobretudo daquela região mais carente de equipamentos e investimentos educacionais (bairros São Jorge, Laranjeiras, Morumbi, Dom Almir), onde se localizará o câmpus, propiciam uma perspectiva, a longo prazo, de mudança na qualificação dos moradores, graças a projetos desenvolvidos pela universidade.

São muitas as vantagens da implantação de um grande câmpus universitário do porte do Glória. Para a cidade, um novo equipamento educacional e cultural, uma nova área verde e de convivência, com geração de empregos e novas atividades, em uma zona urbana que se encontra em expansão.

Para a universidade, pode-se operar uma maior a integração acadêmica das suas atividades (que é extremamente positiva para interdisciplinaridade), e ainda com redução de custos e de dinamização dos serviços; a implantação de uma infraestrutura moderna e construção de novos edifícios corretos do ponto de vista ambiental e urbanístico; a instalação de serviços e equipamentos de uso comum, como espaços de convivência, restaurantes, biblioteca, auditórios, sedes de entidades representativas, dentre outras.

Para que tudo isso possa ser viabilizado, é importante que a universidade disponha de uma equipe para planejar e acompanhar a gestão do plano. Graeff (1984, p. 81) afirma que "a construção do Campus deveria ser encarada como canteiro-laboratório, para reciclagem prática dos docentes, e estágios de treinamento em serviço dos alunos". A Geografia, aliada a outras áreas do conhecimento, tem dado uma importante contribuição nesse projeto.
Não apenas o planejamento, mas a gestão de um câmpus universitário exige o envolvimento de toda a comunidade universitária e externa para garantir uma efetiva institucionalização e uma maior legitimidade das decisões tomadas, mas também para aproximar o câmpus dos seus usuários.

\section{REFERÊNCIAS}

CAETANO, Coraly Gará e DIB, Míriam Michel Cury. A UFU no Imaginário Social. Uberlândia: UFU, 1988.

FERREIRA, William Rodrigues. O Espaço Público nas áreas centrais: a Rua como Referência - um estudo de caso em Uberlândia. Tese de Doutorado (Geografia). Universidade de São Paulo, 2002.

GOMES, Aguinaldo Rodrigues, WARPECHOWSKI, Eduardo Moraes e SOUSA NETTO, Miguel Rodrigues (Org.). Fragmentos imagens memórias: 25 anos de federalização da Universidade Federal de Uberlândia. Uberlândia: Edufu, 2003.

GRAEFF, Edgar A. Anotações sobre Espaço-Tempo na Universidade Brasileira. In: MEC. Campus Universitário - Textos. Brasília: CEDATE, 1984.

INEP - Instituto Nacional de Estudos e Pesquisas Educacionais Anísio Teixeira. Censo da Educação Superior 2010 - MEC. Brasília, 2011. Disponível em http://www.inep.gov.br. Vários acessos em 2011.

. Censo da Educação Escolar 2010 - MEC. Brasília, 2011. Disponível em http://www.inep.gov.br. Vários acessos em 2011.

MINASBIO CONSULTORIAAMBIENTAL e TERRACONSULTORIA. Estudo de Impacto Ambiental e Estudo de Impacto de Vizinhança do Câmpus Glória da Universidade Federal de Uberlândia. Uberlândia: UFU, 2011.

NEIVA, Cláudio Cordeiro. O Meio Ambiente Edificado e o Uso dos Espaços do "Campus". In MEC. Campus Universitário - Textos. Brasília: CEDATE, 1984. 
PRIETO, Élisson Cesar. Os Desafios Institucionais e Municipais para implantação de uma cidade universitária: o Câmpus Glória da Universidade Federal de Uberlândia. Dissertação (mestrado em Geografia) Universidade Federal de Uberlândia. Orientadora: Marlene T. de Muno Colesanti. Uberlândia, 2005.

ROSA, Roberto, DUARTE, Maria Selma, MINEO, Marcela Maria Patriarca, RAVANAZZI, Fredy e VILELA, Lílian de Oliveira. Mapeamento Temático da Bacia do Córrego do Glória em Uberlândia-MG, utilizando o Software Idrisi. 2004 (mimeo).

SETA TOPOGRAFIA. Levantamento Planialtimétrico da Fazenda do Glória, Uberlândia/MG. Agosto a novembro de 2010. FAU/DIROB/UFU. 2010.

SOARES, Beatriz Ribeiro. Uberlândia: da "Cidade Jardim" ao "Portal do Cerrado" - Imagens e Representações no Triângulo Mineiro. Tese de Doutorado (Geografia). Universidade de São Paulo. Orientadora: Prof. Dra. Amália Inês Geraiges de Lemos. São Paulo, 1995.

SOARES, Beatriz Ribeiro; BESSA, Kelly Cristine. As novas redes do cerrado e a realidade urbana brasileira. Boletim Goiano de Geografia, Goiânia, v. 19, n. 2, p. 11-34, 1999.

UFU (Universidade Federal de Uberlândia) Diagnóstico do Espaço Físico da UFU - Levantamento da realidade Física e Ambiental - Relatórios DIROB/ UFU, 2009.

. Plano Diretor do Câmpus Glória - Resolução Conselho Universitário n. ${ }^{\circ}$ 22/2011. Disponível em www.campusgloria.ufu.br. Vários acessos em 2011. 